\title{
Experimental verification of the pedagogical conditions efficacy to build tol- erance among future officers of the National Guard of Ukraine
}

\author{
Mykhailo Medvid ${ }^{1, *}$, Natalia Trobyuk ${ }^{1, * *}$, Marek Storoska ${ }^{2, * * *}$, Olha Lysychkina $^{1, * * * *}$, and Yuliia Medvid ${ }^{1, \dagger}$ \\ ${ }^{1}$ National Academy of the National Guard of Ukraine, 3 Zakhysnykiv Ukrainy Sq., Kharkiv, 61001, Ukraine \\ ${ }^{2}$ College of International Business ISM Slovakia in Prešov, 1 Duchnovičovo námestie, 08001 Prešov, Slovakia
}

\begin{abstract}
This paper highlights the results of the experimental verification of the pedagogical conditions efficacy to build tolerance among future officers of the National Guard of Ukraine (NGU). The identified pedagogical conditions to build the NGU future officers' tolerance are changes to the educational environment, filling the latter with practical examples of the benefits of being tolerant; faculty development and course officers' professional development in terms of building learners' tolerance; identification of the educational components to form tolerance as a quality, corresponding changes to these components' educational and methodological packages. The experiment has demonstrated that the learners of the mixed groups, both females and males, have higher levels of their tolerance in both CG and EG before and after the experiment. Therefore, the pedagogical conditions for the formation of the NGU future officers' tolerance should also embrace, if possible, the formation of mixed training groups of future officers, including both males and females.
\end{abstract}

\section{Introduction}

Representatives of military formations and law enforcement agencies perform combat missions in international peacekeeping operations. Surveys of these categories of individuals have identified a potential risk of conflict between servicemen from various United Nations member states. The main causes of such conflicts are: servicemen's lack of knowledge on the ethical norms of behaviour and culture of the nations the representatives of which participate in peacekeeping operations, as well as of the host state on the territory of which the operation itself is being conducted; gender inequality which is treated differently in different countries, as well as the insufficient training of the servicemen in cross-cultural communication. Under certain circumstances, potential conflicts between the servicemen can become a threat. This is especially dangerous in performing combat service tasks and can lead to such consequences as: failure to perform combat missions; loss of the peacekeeping unit personnel; undermined reputation of the mission and the participating states sending their servicemen to man the peacekeeping units; peacekeeping personnel deportation. A significant contribution to solve such issues is made by the system of the personnel training for military formations and law enforcement agencies of Ukraine, in particular, by assigning an important slot within the system to the formation of such a necessary quality for future officers as tolerance.

\footnotetext{
*e-mail: medvidmm@ukr.net

**e-mail: nataliya_trobyuk@ukr.net

***e-mail: storoska@ismpo.sk

****e-mail: olysychkina@gmail.com

†e-mail: medvidj84@ukr.net
}

\section{Intent of the research justification}

According to N. Skinner and P. Bromley, "strategies for promoting social justice include both individualistic approaches, rooted in the universalism philosophy of human rights, and collectivist approaches, such as groupor issue-specific rights advocated by various social movements. The expansion of human rights education is well documented, but less attention has been given to education for or about other social movements" [1].

The word "tolerant" is interpreted as being able to withstand and endure the adverse effects of any factors; indulgent, lenient toward someone's thoughts, views, beliefs, etc. [2]. The dictionary of social sciences gives a more precise definition: tolerance (Latin tolerantia patience) - 1) tolerance to different views, norms of behaviour, habits, different from those shared by the subject; openness to any ideology, fearlessness of ideas competition; 2) in psychology: complete or partial lack of response to any adverse factor as a result of reduced sensitivity to its influence [3].

The principles of tolerance are stated in the Declaration approved by Resolution 5.61 of the UNESCO General Conference on 16.11.1995 [4]. The document highlights the fact that "tolerance is not only an important principle, but also a necessary condition for peace and social and economic advancement of all peoples". It is also noted that educating for tolerance, formation of learners' tolerance is mandatory in the educational process: "Education for tolerance should be considered an urgent imperative; that is why it is necessary to promote systematic and rational tolerance teaching methods that will address the cultural, social, economic, political and religious sources of 
intolerance - major root of violence and exclusion. Education policies and programmes should contribute to development of understanding, solidarity and tolerance among individuals as well as among ethnic, social, cultural, religious and linguistic groups and nations" [4].

The significance of tolerance for professional activity, its formation in different environments, namely educational, was addressed in a number of scientific works, namely by N. Barbelko [5], O. Bryukhovetska [6], Yu. Irhina [7], A. Molchanova [8], O. Troitska [9] and others. Based on the results of their analysis, we come to the conclusion that to form tolerance in learners it is necessary to introduce changes into the educational environment by creating appropriate pedagogical conditions.

We concur with N. Tarasenko that the educational environment of a higher military educational institution should provide comprehensive training and education of servicemen, i.e. fulfill the main goal - to promote high quality professional training for future officers. In terms of modern problems and challenges, the educational environment should be a certain secure zone in which all subjects of the educational process of higher military education would feel fully realized and protected [10]. According to O. Masliy, the pedagogical conditions for the formation of an officer as a specialist determine the circumstances and methods of management and organization of their education and training in higher military educational institutions that make goal-directed development of the individual's qualities professionally important for this area, and motivate the development of the general capability to establish causal links on the basis of the system complex of professional knowledge, skills, experience, value characteristics and professionally important personal qualities, as well as to adequately influence the functions and tasks performance in this area of military activity [11]. Building positive, constructive relationships is possible only on democratic principles, provided that tolerance is expressed towards each other [12]. Thus, in order to form tolerance in future officers of the National Guard of Ukraine (NGU), changes should be introduced to the educational environment by creating appropriate pedagogical conditions without authoritarianism through organizational, educational and training activities at the level of the group, course, higher educational institution.

\section{Results and discussion}

In order to determine the pedagogical conditions efficacy to build tolerance among future officers of the NGU, a survey of the following stakeholders was conducted: graduates (mostly those who gained practical experience in combat service for at least five years after graduation and became Master Degree candidates at the National Academy of the NGU), learners (cadets), and scientific and pedagogical staff. The focus was on the results of graduates' surveys. All survey results were discussed at meetings of the departments of the Faculty of Humanities. The discussion also revealed a low level of knowledge on tolerance among scientific and pedagogical staff.
Table 1. Learners of the National Academy of the NGU by specialties 253 Command and Control (by the Armed Forces types) and 254 Troops' (Forces') Support, who participated in the experiment

\begin{tabular}{llllll}
\hline $\begin{array}{l}\text { Learners of } \\
\text { the National } \\
\text { Academy of the }\end{array}$ & $\begin{array}{l}\text { CG } \\
\text { males males }\end{array}$ & $\begin{array}{l}\text { EG EG fe- } \\
\text { males males }\end{array}$ & Total \\
NGU & & & & & \\
\hline by Specialty 253 & 68 & 10 & 84 & - & 162 \\
by Specialty 254 & 25 & - & 20 & 9 & 54 \\
Total & 93 & 10 & 104 & 9 & 216 \\
\hline
\end{tabular}

According to the results of the research, the following pedagogical conditions were determined to build tolerance among future officers of the NGU in the process of professional education and training: changes to the educational environment, filling the latter with practical examples of the benefits of being tolerant; faculty development and course officers professional development in terms of building learners' tolerance; identification of the educational components to form tolerance as a quality, corresponding changes to these components' educational and methodological packages.

The results of the pedagogical conditions introduction have been checked with the help of a pedagogical experiment as a research method. Based on the analysis of the latest research publications [1, 5-14], we have developed a program of the pedagogical experiment.

The purpose of the experiment is to verify the efficacy of the pedagogical conditions of building tolerance among the NGU future officers in the process of professional education and training.

Independent variables: pedagogical conditions of building the NGU future officers' tolerance in the process of professional education and training.

Dependent variable: the tolerance level of the NGU future officers in the process of professional education and training.

Participants in the experiment: future officers of the NGU.

Taking into account the training groups composition (groups manned with males only; mixed groups manned with males and females), two educational specialties were chosen: 253 - Military Command and Control (by the Armed Forces types) and 254 - Troops' (Forces') Support (table 1).

According to table 1, the mixed groups are the control group (CG) - a training group of 19 people ( 9 males and 10 females), and the experimental group (EG) - a training group of 29 people (20 males and 9 females).

The EG' and the CG' learners did not differ significantly concerning the level of knowledge, skills, practical skills, thus ensuring the homogeneity of the groups composition at the beginning of the pedagogical experiment.

In compliance with the theoretical provisions, we conducted the research and experiment in three stages (ascertaining, formative, and control). 
Assessment of the level of the NGU future officers' tolerance in the process of professional education and training consisted in the diagnostic assessment conducted with the help of diagnostic tools.

To determine the Cognitive Component, the following methodology was used: "Types and components of tolerance and intolerance" (G. Bardier), "Tolerance Index" (H. Soldatova, O. Kravtsova, O. Khukhlayev, L. Shayherova) [14], Essay "Tolerance is ...".

The Affective-Volitional Component was determined with the help of the Methodology for determining tolerance to uncertainty (S. Badner) [13], "Emotional response scale" (A. Megrabian, N. Epstein), Vitality test (S. Maddy, adaptation by D. Leontev and E. Rasskazova [15]), Assessment of communicative and organizational abilities of the individual (V. Sinyavsky, B. Fedorishin).

The Prognostic-Active Component required the usage of the Methods of diagnostics of communication attitude (V. Boyko) [14], System of exercises, tasks and situations, as well as expert evaluation.

Based on the selected and developed diagnostic methods to assess the formation of tolerance in future officers of the NGU, their levels have been determined as low, average and high.

The learner's level is evaluated as low when he/she possesses limited knowledge of the concepts of tolerance, human rights, types of violence and its manifestation, no knowledge necessary to interact with other individuals in a tolerant manner. $\mathrm{He} / \mathrm{she}$ lacks attention to the interlocutor, shows no interest in the opinion of the other individual. $\mathrm{His} / \mathrm{her}$ decision-making is based on stereotypes. He/she cannot cope with a strong emotional load, has significant difficulties in establishing contact with other people, categoricalness and conservatism in evaluating people. $\mathrm{He} / \mathrm{she}$ is unable to hide and smooth out unpleasant feelings in the face of unsociable qualities of partners, to forgive others for their mistakes.

The learner's level is evaluated as average on the following conditions: he/she possesses sufficient knowledge of the concepts of tolerance, human rights, types of violence and its manifestation, has weak knowledge necessary to interact with other individuals in a tolerant manner. $\mathrm{He} / \mathrm{she}$ tries to be attentive to the interlocutor, does not always show interest in the opinion of others, hardly copes with a strong emotional load. $\mathrm{He} / \mathrm{she}$ is characterized by a weak acceptance and understanding of the individuality of another person. Sometimes there is categoricalness and conservatism in evaluating people. $\mathrm{He} / \mathrm{she}$ tries to hide and smooth out unpleasant feelings when confronted with unsociable qualities of partners, needs time to forgive others for their mistakes.

The learner's level is evaluated as high when he/she possesses very good knowledge of the concepts of tolerance, human rights, types of violence and its manifestation, has very good knowledge necessary to interact with another person in a tolerant manner. $\mathrm{He} / \mathrm{she}$ is attentive to the interlocutor, shows interest in the other person's opinion, copes well with a strong emotional load, is characterized by the acceptance and understanding of the individuality of another person, non-categorical and non-
Table 2. The NGU future officers' tolerance levels formed in the process of professional education and training (persons / percent)

\begin{tabular}{llll}
\hline Component & Level & $\begin{array}{l}\text { EG be- } \\
\text { fore } \\
\text { experi- } \\
\text { ment }\end{array}$ & $\begin{array}{l}\text { CG be- } \\
\text { fore the } \\
\text { experi- } \\
\text { ment }\end{array}$ \\
\hline Cognitive & Low & $52 / 46$ & $49 / 48$ \\
Cognitive & Average $35 / 31$ & $29 / 28$ \\
Cognitive & High & $26 / 23$ & $25 / 24$ \\
Affective-Volitional & Low & $57 / 50$ & $55 / 53$ \\
Affective-Volitional & Average $36 / 32$ & $29 / 28$ \\
Affective-Volitional & High & $20 / 18$ & $19 / 18$ \\
Prognostic-Active & Low & $46 / 41$ & $41 / 40$ \\
Prognostic-Active & Average $36 / 32$ & $35 / 34$ \\
Prognostic-Active & High & $31 / 27$ & $27 / 26$ \\
\hline
\end{tabular}

conservative judgment about people, absence of unpleasant feelings in the face of uncommunicative qualities of partners, ability to forgive others for their mistakes.

The level of a certain component of tolerance formation was determined by the majority of the obtained levels of tolerance formation according to all the methods of this component. The level of tolerance formation of the future officer was determined by the majority of the obtained levels of tolerance formation by the components of readiness.

After identifying the NGU future officers' tolerance level formed in the process of professional education and training according to the defined tools, the results of the ascertaining experiment were attained (table 2). According to the calculations done by the computer program "Statistics in Pedagogy" [16], the following data were obtained.

The pedagogical conditions were introduced in EG as follows.

The first pedagogical condition. This requires that when there is an exchange of ideas, opinions, when there is learning and communication, tolerance should become the norm of behaviour and mutual respect. Knowledge of tolerance helps to convince everyone of the appropriateness of their decisions, and includes awareness of the actions consequences, understanding the limits of tolerance, as well as information about possible and necessary alternative actions. However, knowledge alone is not a strong enough stimulus for tolerant behaviour in conflict situations. To this end, it is necessary to develop certain skills that enhance future officers propensity to be tolerant and take appropriate actions. Such abilities include: the ability to dialogue, communicate, intelligently listen to others and formulate one's own views, rights and needs so that the others can understand them; the ability to look at the problem realistically and recognize the position of the other; ability to use the models of constructive and democratic conflict resolution; understanding the fundamental limitations and subjectivity of any interpretive model, the feeling of silently pretending something that is sometimes a prerequisite for conflict.

The choice of methods, means or technologies of learning is important for the effective education of a tol- 
erant personality of a serviceman in the system of higher educational institutions. Interactive teaching and learning methods have the greatest educational potential: role play, discussion, project method, "fish bowl", brainstorming, Synanon method, etc. which allow not only to develop creative potential, but also to develop a tolerant personality with developed qualities: responsibility, independence, adequacy of self-esteem, willingness to take risks, creativity.

For example, learning with the use of the Synanon method takes place in the form of a game using the socalled "hot chair". Each participant of the lesson takes a seat on a chair in front of the audience and is interviewed by the groupmates on a specific educational topic (i.e. the task of deepening and systematizing theoretical knowledge is being solved). At the same time, the members of the group have the right to "provoke" him/her to aggressive behaviour with their questions, and his/her task is to behave tolerantly. Thus, in addition to the professional knowledge, the participants of the training should learn about emotional balance, tolerance to negative emotional actions, improve their character traits, namely volitional qualities.

In the process of interactive learning, as a rule, actions are analyzed, behaviour patterns change, knowledge and skills are more consciously acquired, so it makes sense to say that interactive methods are strong not only as a means of improving learning but also as a means of strengthening educational influences.

The second pedagogical condition. In the higher educational institution, the development of the system of internal quality assurance receives considerable attention, in particular concerning the professional development of the faculty [17]. In accordance with the requirements of regulations at the National Academy of the NGU, the opportunities have been created for advanced training in the formation and development of personal tolerance and the ability to develop tolerance in other members of the academic community, including learners. For this purpose, online courses of the Prometheus platform is used, namely the course "Culture of tolerance: how to build a society that is comfortable for all" [18]. Corresponding changes have been introduced to the curricula of the faculty development program "Staff support of the educational activities of a higher military educational institution" (the mentioned above issues are addressed within the modules "Pedagogical and Professional Psychology" and "Professional Culture of Higher Military School Lecturer") [19], and "Faculty development of scientific and pedagogical and pedagogical staff for the educational process enhancement" (the mentioned above issues are addressed in the modules "Topical problems of psychology of higher education" and "Strategic communications in educational process") [20]. Despite the fact that there are restrictions for scientific and pedagogical staff to study and do internship abroad, the representatives of the higher educational institution have improved their skills abroad on the development of tolerance in society. Almost all scientific and pedagogical staff who realize the educational components in the training groups of the EG, as well as course officers of these groups, have successfully completed at least one of these courses.

The third pedagogical condition. We have chosen a socio-psychological training as a means of purposeful formation of tolerance.

In general, the philosophy of education considers training as an effective technology of active learning, in the process of which professional qualities of the individual are quickly formed, the individual quickly adapts to a new environment along with interpersonal communication active development and implementation of the requirements of society and the state as for the individual.

We propose to apply the training that affects the development of the NGU future officers' tolerance in the course "Psychology of Extreme Activities". The purpose of the training is to consolidate the future officers' knowledge of the components of tolerance, teach them to understand and respect their activities, be tolerant in communication, show the importance of tolerant behaviour when interacting with others, develop skills of conflict-free interaction, endurance, self-control, ability to tolerate unfavorable influences for a long time.

The training includes the exercise with the following purposes: psycho-diagnostics and assessment of personal tolerance; development of a sense of mutual understanding among the participants of the process; development of social perception; development of the ability to tolerantly (not aggressively) express their negative feelings.

The proposed training is not able to solve all the tasks related to the formation of the skills that allow confident and conflict-free performance in fulfilling the tasks of the NGU, but it can help the NGU servicemen to skillfully regulate their interaction with the activity environment [21].

After examining the NGU future officers' tolerance formed in the process of professional education and training according to the defined tools, the results of the experiment were attained. The results of diagnostic assessment of the NGU future officers' tolerance built in the educational process and training of the EG and the CG are given in table 3 .

The empirical data analysis shows positive dynamics of tolerance among the NGU future officers in the process of professional education and training in the EG. It has been found out that during the experiment the number of the EG learners with the low level of tolerance among the NGU future officers has significantly decreased (by the cognitive component - by $27 \%$, by the affective-volitional component - by $25 \%$, by the prognostic-active component - by $19 \%$ ). At the same time, the number of the NGU future officers with the high level of tolerance has increased (by the cognitive component - by $38 \%$, by the affectivevolitional - by $19 \%$, by the prognostic-active - by $22 \%$ ). In the CG the changes are insignificant.

During the experiment, it came out that both female and male learners of the mixed groups possess higher levels of tolerance in both CG and EG before and after the experiment. From this perspective, the formation of mixed training groups of future officers, including both males and females when possible, should be added to the pedagogical 
Table 3. Dynamics of the NGU future officers' tolerance levels formed in the process of professional education and training (persons / percent)

\begin{tabular}{llllll}
\hline Component & Level & $\begin{array}{l}\text { EG after the } \\
\text { experiment }\end{array}$ & EG dynamics & $\begin{array}{l}\text { CG after the } \\
\text { Synanon method }\end{array}$ & CG dynamics \\
\hline Cognitive & Low & $21 / 19$ & $-31 /-27$ & $43 / 42$ & $-6 /-6$ \\
Cognitive & Average & $23 / 20$ & $-12 /-11$ & $26 / 25$ & $-3 /-3$ \\
Cognitive & High & $69 / 61$ & $43 / 38$ & $34 / 33$ & $9 / 9$ \\
Affective-Volitional & Low & $29 / 26$ & $-28 /-25$ & $49 / 48$ & $-6 /-6$ \\
Affective-Volitional & Average & $43 / 38$ & $7 / 6$ & $31 / 30$ & $2 / 2$ \\
Affective-Volitional & High & $41 / 36$ & $21 / 19$ & $23 / 22$ & $4 / 48$ \\
Prognostic-Active & Low & $24 / 21$ & $-22 /-19$ & $35 / 34$ & $-6 /-6$ \\
Prognostic-Active & Average & $33 / 29$ & $-3 /-3$ & $34 / 33$ & $-1 /-1$ \\
Prognostic-Active & High & $56 / 50$ & $25 / 22$ & $34 / 33$ & $7 / 7$ \\
\hline
\end{tabular}

conditions for the formation of the NGU future officers' tolerance.

\section{Conclusion}

The comparative analysis of the experimental data shows the increase in the percentage of the EG learners (compared to CG) with the high level of the NGU future officers' tolerance in the educational process (by the cognitive component - by $38 \%$, by the affective-volitional component - by $19 \%$, by the prognostic-active component - by $22 \%$ ).

While comparing the results of the experiment before and after, it was obtained: in the CG the empirical values of the criterion $\chi^{2}$ are lower than the critical ones, the characteristics of the compared groups coincide at the level of significance of 0.05 ; in the EG the empirical values of the criterion $\chi^{2}$ are higher than the critical ones, the reliability of the difference in the characteristics of the compared groups is $95 \%$.

Thus, the results are reliable and give grounds for the conclusion that the differences in the values of tolerance levels among the NGU future officers in the process of professional education and training in the EG and the CG are not accidental, and highlight the effectiveness of the identified pedagogical conditions to build the NGU future officers' tolerance:

- changes to the educational environment, filling the latter with practical examples of the benefits of being tolerant;

- faculty development and course officers' professional development in terms of building learners' tolerance;

- identification of the educational components to form tolerance as a quality, corresponding changes to these components' educational and methodological packages.

During the experiment, we noticed that the learners of the mixed groups, both females and males, have higher levels of their tolerance in both CG and EG before and after the experiment.

Therefore, the pedagogical conditions for the formation of the NGU future officers' tolerance should also include, if possible, the formation of mixed training groups of future officers, including both males and females.

\section{References}

[1] N. Skinner, P. Bromley, Comparative Education Review 63, 502 (2019)

[2] T.V. Korolova, L.P. Kovryga, Interpretive Dictionary of the Ukrainian Language (Kharkiv, 2002)

[3] O.G. Danilian, M.I. Panova, Modern Dictionary of Social Sciences (Kharkiv, 2006)

[4] UNESCO, Declaration of principles on tolerance (1995), http://portal.unesco.org/en/ev. php-URL_ID=13175\&URL_DO=DO_TOPIC\&URL_ SECTION=201.html

[5] N.S. Barbelko, Ph.D. thesis, Uman State Pedagogical University named after P. Tychyna (2015)

[6] O.V. Bryukhovetska, Actual problems of psychology pp. 3-8 (2015)

[7] Y.V. Irhina, Ph.D. thesis, South Ukrainian National Pedagogical University named after K. D. Ushinsky (2011)

[8] A.O. Molchanova, Tolerance as a value basis of a teacher's professional activity (Institute of Pedagogical and Adult Education of the National Academy of Educational Sciences of Ukraine, Kyiv, 2013)

[9] O.M. Troitska, Ph.D. thesis, Institute of Pedagogy of National Academy of Educational Sciences of Ukraine (2017)

[10] N. Tarasenko, Pedagogical sciences pp. 207-219 (2016)

[11] O.M. Masliy, System of professional training of future officers of missile and artillery armament in higher military educational institutions: theoretical and methodological aspects (FOP Melnyk A. A., Khmelnytsky, 2019)

[12] O.V. Stoliarenko, O.V. Stoliarenko, Education of the culture of tolerant relationships among student youth (Nilan-LTD, Vinnytsia, 2014)

[13] G.L. Bardier, Scientific basis of social psychologyof tolerance (MIRS Publishing House, St-Petersburg, 2007)

[14] G.U. Soldatova, L.A. Shaigerova, Psychodiagnostics of personality tolerance (Smysl, Moscow, 2008)

[15] D.A. Leontev, E.I. Rasskazova, Test zhiznestoikosti (Vitality test) (Moscow, 2006) 
[16] Computer program "statistics in pedagogy" (2015), http://www . mtas . ru/uploads/stat . zip

[17] M. Medvid, V. Dem'yanyshyn, I. Chernichenko, V. Honchar, V. Liutyi, The Development of Readiness for the Educational Activities in Teachers of Higher Military Educational Institutions, in Proceedings of the 20203 rd International Seminar on Education Research and Social Science (ISERSS 2020) (Atlantis Press, 2021), pp. 416-422, ISBN 978-94-6239-3165 , ISSN 2352-5398

[18] Culture of tolerance: how to build a society comfortable for all (2020), https://courses. prometheus.org.ua/courses/course-v1: Prometheus+TOL101+2020_T3/about

[19] The staff support in the educational process at the higher military educational institution (2020), https://cutt.1y/4zi396K

[20] The advanced training of scientific and pedagoical, and pedagogical staff on the educational process enhancement (2020), https: //cutt. ly/Mzi8fW8

[21] N. Trobiuk, Journal of Pedagogy and Educational Management pp. 160-167 (2020) 